\title{
ПРИМЕНЕНИЕ КЕРАМИЧЕСКИХ ВКЛАДОК В ОРТОПЕДИЧЕСКОЙ СТОМАТОЛОГИИ ПРИ ВОССТАНОВЛЕНИИ ДЕФЕКТОВ В КОРОНКОВОЙ ЧАСТИ ЗУБА
}

\section{APPLICATION OF CERAMIC INLAYS IN ORTHOPEDIC DENTISTRY IN RESTORING DEFECTS IN THE CROWN PART OF THE TOOTH}

S. Romish

Summary. The article describes the technology of microprosthetics in the provision of dental orthopedic care using ceramic inlays in order to restore the shape and function of the tooth; the advantages, disadvantages, indications and contraindications of this technology are considered.

Keywords: microprosthetics, inlays, InLay, OnLay, OverLay, PinLay, inlay prosthetics technology, CEREC.
$\Pi$ ротезирование вкладками и микропротезирование в целом представляют собой относительно новый раздел ортопедической стоматологии.

Микропротезирование - это изготовление из керамики замещающей конструкции для недостающей или разрушенной части зуба и её фиксация на сохранившуюся часть зуба. В результате воссоздаётся анатомическая форма, функциональная целостность и эстетический вид здорового зуба. К микропротезам относятся вкладки и различные разновидности виниров, которые имеют разное назначение. Так, виниры используются для восстановления только передней (фронтальной) и боковой (щёчной) части зубов, а вкладки применяются для восстановления (реконструкции) зубов при дефектах жевательных и контактных поверхностей.

В данной статье рассматриваются керамические вкладки.

\section{Обшие свеАения}

Вкладками называют протезы, которые восстанавливают анатомическую форму зуба, заполняя собой дефект в его коронке. Вкладки относят к микропротезам и применяют для восстановления формы и функции коронковой части зуба, нарушенной в результате кариозных

\author{
Ромиш Собир Комолзод \\ К.м.Н., дочент, ГАУ ДПО «Институт \\ усовершенствования врачей» Министерства \\ здравоохранения Чувашской Республики \\ rom-sobir@yandex.ru
}

Аннотация. Приведено описание технологии микропротезирования при оказании стоматологической ортопедической помощи сприменением керамических вкладок в целях восстановления формы и функции зуба; рассмотрены преимущества, недостатки, показания и противопоказания данной технологии.

Ключевые слова: микропротезирование, вкладки, InLay, OnLay, OverLay, PinLay, технология протезирования вкладками, CEREC.

и некариозных поражений. Вкладки используют также при замковой фиксации и в качестве опоры несъёмных и съёмных протезов и шинирующих конструкций $[3,5]$.

Зубная керамическая вкладка представляет собой искусственный миниатюрный протез, устанавливаемый на месте удаленных пораженных тканей для воспроизведения анатомической формы зуба. По сути, такие вкладки являются подобием пломбы, созданной в лабораторных условиях по заранее снимаемому оттиску. Такая технология относится к одной из разновидностей несъёмного протезирования. Эстетические и визуальные характеристики существенно отличают зубную керамическую вкладку от обыкновенной пломбы. Их используют в основном на задних зубах в качестве альтернативы классическому пломбированию, так как они имеют ряд преимуществ - как в плане функциональности, так и в плане эстетичности. Вкладки применяют при кариозных полостях I, II, реже III-IV классов по Блэку (полости V-го класса восстанавливаются только пломбой). Это связано с тем, что при полостях III-V классов вкладки могут уступать в эстетике композитным реставрациям, требуя при этом большей инвазивности и значительных трудозатрат.

Таким образом, керамические вкладки эффективны в тех случаях, когда пломбу поставить невозможно, 
например, если после лечения заболевания образовалась слишком большая полость, и классическая пломба не будет надёжно закреплена в полости.

Керамические вкладки создаются в зуботехнической лаборатории, для их изготовления применяются не композитные материалы, а керамика или цирконий. Такие материалы соответствуют зубным тканям как по прочности, так и по цвету $[1,2,5]$. Существуют и другие материалы, применяемые для изготовления вкладок и накладок, однако керамика считается наиболее оптимальной для таких частичных реставраций.

\section{ВиАы}

керамических вк^аАок

Выделяют четыре основных вида вкладок в зависимости от формы:

1. InLay - тело вкладки не выходит за пределы бугров зуба (не затрагивают бугорки зуба).

2. OnLay - тело вкладки полностью перекрывает один или более бугров зуба (замещают внутренние скаты бугорков).

3. OverLay - тело вкладки охватывает 4 из 5 стенок коронки зуба (перекрывают бугры зуба полностью).

4. PinLay - вкладка имеет дополнительный элемент фиксации - штифт (пин).

Вкладки типа InLay являются наименее инвазивными, поскольку практически не затрагивают бугры зуба. Вкладки OnLay замещают внутренние скаты бугров, a OverLay перекрывает полностью хотя бы один бугор. Если OverLay перекрывает все бугры, то в этом случае он практически не отличается от трёхчетвертной коронки. Вкладки PinLay характеризуются наличием штифта пина $[4,6]$.

\section{Технология \\ изготовления вкАаАОк}

В практической стоматологии при использовании классических пломб все манипуляции проводятся в терапевтическом кабинете, однако керамические микропротезы (вкладки, виниры и пр.) должны изготавливаться в зуботехнической лаборатории ортопедического отделения. Кроме того, при изготовлении керамических вкладок в лаборатории имеется возможность существенно улучшить их физические свойства, такие как прочность, устойчивость к стиранию, водопоглощение и цветостойкость.

Изготовление керамических вкладок, как правило, требует несколько визитов пациента и может занять время около одной недели.
В первое посещение врач-стоматолог-ортопед проводит санацию полости рта, проводит препарирование дефектной области зуба и снимает анатомический оттиск (слепок), который передаёт в зуботехническую лабораторию. При препарировании необходимо создать достаточное пространство для будущей вкладки или накладки. Толщина этих микропротезов должна быть не менее 0,5-1,5 мм в зависимости от применяемого материала, чтобы обеспечить прочность конструкции и предотвратить возможные поломки.

Керамические зубные вкладки изготавливаются в лабораторных условиях, благодаря чему сводится до минимума контакт пациента с вредными для его здоровья веществами [1, 2]. Вкладки изготавливаются из оксида циркония или прессованной керамики по специальной технологии - либо методом послойного нанесения, либо путём компьютерного фрезерования. В результате получается вкладка, полностью соответствующая отсутствующей части зуба.

На заключительном этапе вкладка устанавливается на дефектный зуб и производится её припасовка в полости рта. После соответствующей подготовки микропротез фиксируется, и окончательно выверяются окклюзионные контакты. Фиксацию вкладок проводят с помощью стеклоиономерного цемента или, чаще всего, композита двойного отверждения (светового и химического).

\section{Способ компьютерного фрезерования вк^алок из керамики}

С целью оптимизации и повышения качества изготовления вкладки созданы компьютерные технологии фрезерования вкладок из керамических материалов (система CEREC). Применение этой технологии исключает использование труда зубного техника, позволяет изготавливать и устанавливать керамические вкладки непосредственно в клинике за один этап. По этой методике вкладки изготавливают из стандартного керамического блока, поэтому такие микропротезы характеризуются более высокими показателями прочности.

Формирование полости под вкладку проводится по общепринятым правилам, с особенностями препарирования под керамические конструкции. Рекомендуется формировать полость со слегка дивергирующими стенками (не более 4-6). Это необходимо для получения точного оптического оттиска, на котором в одной проекции одновременно видны внутренние и наружные края полости.

После этого с помощью интраоральной (внутриротовой) видеокамеры получают оптический оттиск 
протезируемого зуба и рядом стоящих зубов, а также окклюзионной поверхности зубов-антагонистов. Изображение полости, информация о её размерах и форме, а также о контурах жевательной поверхности зубов-антагонистов передаются в компьютер. Это изображение обрабатывается специальной программой, после чего врач-стоматолог осуществляет компьютерное моделирование конструкции с учетом всех факторов. На основании виртуальной модели вкладки на специальном фрезерно-шлифовальном станке с программным управлением производится изготовление вкладки из стандартной керамической заготовки.

К преимуществам компьютерной технологии изготовления вкладок относится исключение клинического этапа получения оттисков и технического этапа получения моделей, что обеспечивает экономию времени врача, техника и пациента. Кроме того, отсутствие необходимости получения оттисков и моделей обусловливает повышение точности изготовления вкладок и накладок.

\section{Преимушества и неАостатки}

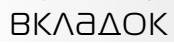

При стоматологическом ортопедическом лечении зубов керамические вкладки имеют ряд преимуществ, в частности, по сравнению с пломбами (композитными материалами):

- обеспечивают возможность полного восстановления анатомической формы зуба (разрушенные бугры, боковые эмалевые валики на жевательной поверхности) для нормализации функций жевательного аппарата;

- выдерживают повышенные жевательные нагрузки (износостойкие) и не деформируются со временем. Вкладки не подвержены усадке, которая бывает у пломбировочных материалов. Другими словами, они заметно стабильнее, чем пломбы из синтетических материалов;

- цветостойкие, т.е. не меняют со временем цвет и эстетично сохраняют такой же вид, как и у натурального зуба;

- не вызывают аллергических реакций у пациента;

- позволяют добиться более плотного прилегания к поврежденным или отсутствующим тканям зуба.

Керамические вкладки имеют и недостатки:

- большие трудозатраты при изготовлении;

- работа выполняется с участием зуботехнической лаборатории;

- высокая стоимость материалов для создания вкладки;

- вследствие вышеперечисленного повышается стоимость микропротеза;
- сложность устранения дефектов готовой керамической вкладки.

Показания и противопоказания к применению вкладок

Для применения вкладок существует ряд показаний и противопоказаний.

\section{Показания}

- нарушение анатомической формы и цвета зубов как при врождённых (дефекты формы, аномалии величины, несовершенный амелогенез и гипоплазия эмали), так и при приобретенных патологических состояниях (травмы, клиновидные дефекты, кариес, изменение цвета при флюорозе, пигментные пятна эмали, возрастные изменения цвета, «тетрациклиновые» зубы и др.);

- повышенное стирание твёрдых тканей зубов;

- дефекты твёрдых тканей, замещаемые перед съёмным или несъёмным протезированием;

- аллергия на пластмассы и композиты, используемые для прямой реставрации зуба;

- заболевания пародонта, периодонта и пр.

\section{Противопоказания}

- низкие, мелкие и плоские коронки отдельных зубов с живой (витальной) пульпой;

- крайние формы повышенной стираемости зубов;

- обширные дефекты зуба с тонкими, хрупкими стенками;

- парафункции жевательных мышц (к примеру, бруксизм).

\section{Зак^ючение}

Стоматологические вкладки из керамики являются одним из наиболее эффективных методов восстановления целостности (анатомической формы и функции) зубов.

Даже в самых тяжёлых случаях, когда зуб практически полностью разрушен, его можно восстановить таким образом, чтобы зубной ряд выглядел максимально эстетично. Вкладку крайне сложно отличить от самого зуба, так как полировка сводит к минимуму все заметные изменения его формы, разницу в структуре зуба и керамики. Между зубом и вкладкой фактически не остаётся зазоров, на месте которых возможно образование вторичного кариеса. Более того, по своим свойствам керамика максимально приближена к свойствам натуральных зубов, его тканям, поэтому по итогам ортопедического лечения зуб будет наиболее точно соответ- 
ствовать своему изначальному состоянию, насколько это вообще возможно. Кроме того, пациент не будет при этом страдать от неприятных ощущений, с которыми зачастую приходится сталкиваться людям после установки зубных пломб и прочих восстановительных процедур.

Относительным недостатком таких вкладок является более высокая по сравнению с пломбированием стоимость. Однако цена на такой вид стоматологических услуг в большей степени компенсируется продолжительным сроком службы, высокими эстетическими и функциональными характеристиками керамических вкладок. Поэтому восстановление зубов керамическими вкладками становится всё более востребованным среди пациентов.

Однако нельзя говорить о том, что в будущем керамические вкладки полностью заменят пломбы, так как при незначительных повреждениях целесообразно устанавливать именно пломбы. При обширном же разрушении восстановление пломбой бесполезно и требуется применения керамической вкладки.

\section{ЛИТЕРАТУРА}

1. Ортопедическая стоматология. Прикладное материаловедение. Учебник / В. Н. Трезубов, Л. М. Мишнев, В. В. Трезубов. - М.: МЕДпресс-информ, 2017.

2. Стоматологическое материаловедение. Наглядное учебное пособие / под ред. Энтони фон Фраунхофера, — М.: ГЭОТАР-Медиа, 2017.

3. Керамические зубные вкладки и вестибулярные облицовки. Учебное пособие / под ред. С. Б. Фищева, М. Ф. Сухарева. — СПб.: СпецЛит, 2018.

4. Чайка 3. Оптимизация реставрации зубов керамическими вкладками. Микропротезирование / 3. Чайка, Г. И. Рoнь. — Lambert Academic Publishing, 2012.

5. Гарбер Д. Эстетическая реставрация боковых зубов. Вкладки и накладки / Д. Гарбер, Р. Голдштейн.— М.: МЕДпресс-информ, 2009.

6. Конструирование несъёмных протезов с применением вкладок / Е. Н. Жулев и др.— Н. Новгород.: Изд-во Нижегородской гос. мед. академии, 2005. 